\title{
Adoption of Social Determinants of Health EHR Tools by Community Health Centers
}

\author{
Racbel Gold, $P b D, M P H^{1,2}$ \\ Arwen Bunce, $M A^{1}$ \\ Stuart Cowburn, $\mathrm{MPH}^{2}$ \\ Katie Dambrun, $\mathrm{MPH}^{2}$ \\ Marla Dearing ${ }^{2}$ \\ Mary Middendorf ${ }^{2}$ \\ Ned Mossman, $\mathrm{MPH}^{2}$ \\ Celine Hollombe, $M P H^{1}$ \\ Peter Mabr, MD \\ Gerardo Melgar, $M D^{4}$ \\ James Davis ${ }^{1}$ \\ Laura Gottlieb, MD, MPH \\ Erika Cottrell, $P b D, M P P^{2}$ \\ 'Kaiser Permanente Center for Health \\ Research, Portland, Oregon \\ ${ }^{2} \mathrm{OCHIN}$, Inc, Portland, Oregon \\ ${ }^{3}$ Multnomah County Health Department, \\ Portland, Oregon \\ ${ }^{4}$ Cowlitz Family Health Center, Longview, \\ Washington \\ ${ }^{5}$ University of California, San Francisco, \\ California
}

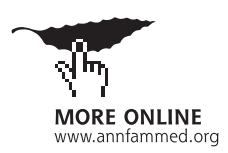

Conflicts of interest: authors report none.

\section{CORRESPONDING AUTHOR}

Rachel Gold, PhD, MPH

Kaiser Permanente Center for Health

Research

3800 N Interstate Ave

Portland, OR 97227

Rachel.Gold@kpchr.org

\begin{abstract}
PURPOSE This pilot study assessed the feasibility of implementing electronic health record (EHR) tools for collecting, reviewing, and acting on patientreported social determinants of health (SDH) data in community health centers (CHCs). We believe it is the first such US study.
\end{abstract}

METHODS We implemented a suite of SDH data tools in 3 Pacific Northwest CHCs in June 2016, and used mixed methods to assess their adoption through July 2017. We modified the tools at clinic request; for example, we added questions that ask if the patient wanted assistance with SDH needs.

RESULTS Social determinants of health data were collected on 1,130 patients during the study period; $97 \%$ to $99 \%$ of screened patients $(n=1,098)$ had $\geq 1$ SDH need documented in the EHR, of whom 211 (19\%) had an EHR-documented SDH referral. Only $15 \%$ to $21 \%$ of patients with a documented SDH need indicated wanting help. Examples of lessons learned on adoption of EHR SDH tools indicate that clinics should: consider how to best integrate tools into existing workflow processes; ensure that staff tasked with SDH efforts receive adequate tool training and access; and consider that timing of data entry impacts how and when SDH data can be used.

CONCLUSIONS Our results indicate that adoption of systematic EHR-based SDH documentation may be feasible, but substantial barriers to adoption exist. Lessons from this study may inform primary care providers seeking to implement SDH-related efforts, and related health policies. Far more research is needed to address implementation barriers related to SDH documentation in EHRs.

Ann Fam Med 2018;16:399-407. https://doi.org/10.1370/afm.2275.

\section{INTRODUCTION}

$\mathrm{N}$ umerous health care systems are exploring how to incorporate social needs documentation and intervention into routine care. ${ }^{1-4}$ These efforts are based on strong evidence that patients' social and economic contexts (their social determinants of health $[\mathrm{SDH}]$ ) shape health, ${ }^{5-15}$ and on nascent evidence that clinic-based SDH screening and intervention can improve health. ${ }^{2,16-20}$

Standardized SDH screening documentation in electronic health records (EHRs) is endorsed by the National Academy of Medicine, the Medicare Access and Children's Health Information Program Reauthorization Act of 2015, the 2016 Centers for Medicare and Medicaid Services' Quality Strategy, and other professional organizations. ${ }^{21-25}$ Such documentation is especially relevant to community health centers (CHCs), whose vulnerable patients are likely to experience social and economic risks associated with poor health. ${ }^{26-36}$ Community health centers' past efforts to integrate social and medical needs ${ }^{37}$ were typically ad hoc and rarely documented in EHRs. ${ }^{3,4,38}$ Little is known about how to capture and present $\mathrm{SDH}$ information in CHCs' EHRs, or how to integrate EHR-based SDH documentation into $\mathrm{CHC}$ workflows. ${ }^{19,39}$

We conducted a pilot study to develop EHR-based SDH data tools for documenting and summarizing SDH screening results and making 
SDH-related referrals, and then assessed adoption of these tools by CHCs. We previously described the tools' development (Table 1 for SDH data tools and domains; Supplemental Appendix 1, available at http:// www.annfammed.org/content/16/5/399/suppl/DC1/, for the screening questions). ${ }^{40}$ The tools built on the Protocol for Responding to and Assessing Patient Assets, Risks, and Experiences (PRAPARE), a national effort to develop a standardized approach to SDH documentation by CHCs. This effort prioritized SDH domains for screening in CHCs, included recommendations for presenting SDH data in EHRs, ${ }^{41,42}$ and incorporated many of the National Academy of Medicine's SDH domains. ${ }^{22}$ Our SDH data tools represent the Epic (Epic Systems Corp) version of PRAPARE. The tools were developed using a stakeholder-driven process, in which diverse CHC staff reviewed tool prototypes that we iterated based on their feedback. The prototypes were informed by expert knowledge of standard EHR functionalities.

This paper focuses on describing and evaluating: how $3 \mathrm{CHCs}$ adopted these EHR tools designed for SDH screening documentation and action in standard workflows, facilitators and barriers to this adoption; and the SDH needs documented via the EHR tools.
We believe this is the first US study on the collection of SDH data using EHR-based tools in CHCs.

\section{METHODS}

\section{Setting}

This work was conducted at OCHIN, a non-profit host of an Epic EHR for $>600$ primary care CHCs, the nation's largest $\mathrm{CHC}$ network on a single EHR system. We recruited 3 OCHIN member CHCs in late 2015, based on clinic interest in SDH screening and proximity to OCHIN's headquarters. Like most CHCs, the study clinics' patient populations are primarily publicly insured or uninsured and aged $<65$ years, $10 \%$ to $31 \%$ are non-white and $10 \%$ to $30 \%$ are of Hispanic ethnicity (Table 2).

\section{Tool Implementation}

In June 2016, the SDH data collection and summary tools were deployed to all OCHIN CHCs; the referral tools were deployed only in the 3 pilot $\mathrm{CHCs}$ because they required local customization (Table 1). We used several implementation strategies ${ }^{43}$ to support tool adoption in the pilot CHCs. Each clinic identified an SDH champion and staff members were engaged in tool development. ${ }^{40}$ We held 2 trainings for clinic staff before the tools' release: 8 staff from the 3 pilot sites were invited, and encouraged to invite other staff to attend, 25 people attended. We provided written materials explaining $\mathrm{SDH}$, the $\mathrm{SDH}$ data tools and their potential uses, and paper versions of the SDH questionnaire in English and Spanish.

During tool testing and use, the pilot clinics requested several tool modifications. These were made as soon as feasible given the need to obtain stakeholder consensus and work within OCHIN's change processes. A "no follow-up needed" referral option was added in time for the initial, June 2016, tool release. Questions asking whether the patient wanted assistance with needs identified in the SDH questionnaire, and what kind of assistance (informational handout or contact from clinic staff), were requested in February 2017 and added in May 2017. Also in May 2017, we added reportable 
Table 2. Patient and Visit Characteristics of Patients Seen During the Study Period, and of Those Screened for SDH, by Clinic

\begin{tabular}{|c|c|c|c|c|c|c|}
\hline \multirow[b]{2}{*}{ Patient Characteristics } & \multicolumn{2}{|c|}{ Clinic A } & \multicolumn{2}{|c|}{ Clinic B } & \multicolumn{2}{|c|}{ Clinic C } \\
\hline & $\begin{array}{l}\text { Total Patients } \\
\text { No. }(\%)\end{array}$ & $\begin{array}{c}\text { Screened } \\
\text { Patients } \\
\text { No. (\%) }\end{array}$ & $\begin{array}{c}\text { Total Patients } \\
\text { No. }(\%)\end{array}$ & $\begin{array}{l}\text { Screened } \\
\text { Patients } \\
\text { No. (\%) }\end{array}$ & $\begin{array}{l}\text { Total Patients } \\
\text { No. (\%) }\end{array}$ & $\begin{array}{l}\text { Screened } \\
\text { Patients } \\
\text { No. (\%) }\end{array}$ \\
\hline Number of patients & $4,208(100.0)$ & $602(14.3)$ & $2,126(100.0)$ & $379(17.8)$ & $3,741(100.0)$ & $149(4.0)$ \\
\hline \multicolumn{7}{|l|}{ Race } \\
\hline American Indian/AK Native & $122(2.9)$ & $14(2.3)$ & $56(2.6)$ & $9(2.4)$ & $39(1.0)$ & $0(0.0)$ \\
\hline Asian & $50(1.2)$ & $5(0.8)$ & $30(1.4)$ & $4(1.1)$ & $494(13.2)$ & $9(6.0)$ \\
\hline Black/African American & $62(1.5)$ & $8(1.3)$ & $31(1.5)$ & $5(1.3)$ & $303(8.1)$ & $9(6.0)$ \\
\hline Native Hawaiian/PI & $39(0.9)$ & $6(1.0)$ & $15(0.7)$ & $5(1.3)$ & $21(0.6)$ & $2(1.3)$ \\
\hline White & $3,798(90.3)$ & $541(89.9)$ & $1,726(81.2)$ & $322(85.0)$ & $2,569(68.7)$ & $105(70.5)$ \\
\hline Multiple races & $73(1.7)$ & $12(2.0)$ & $88(4.1)$ & $13(3.4)$ & $70(1.9)$ & $4(2.7)$ \\
\hline Unknown & $64(1.5)$ & $16(2.7)$ & $180(8.5)$ & $21(5.5)$ & $245(6.5)$ & $20(13.4)$ \\
\hline \multicolumn{7}{|l|}{ Hispanic } \\
\hline Yes & $403(9.6)$ & $40(6.6)$ & $627(29.5)$ & $75(19.8)$ & $531(14.2)$ & $22(14.8)$ \\
\hline No & $3,710(88.2)$ & $545(90.5)$ & $1,457(68.5)$ & $292(77.0)$ & $3,110(83.1)$ & $121(81.2)$ \\
\hline Unknown & $95(2.3)$ & $17(2.8)$ & $42(2.0)$ & $12(3.2)$ & $100(2.7)$ & $6(4.0)$ \\
\hline \multicolumn{7}{|l|}{ Sex } \\
\hline Female & $2,416(57.4)$ & $315(52.3)$ & $1,287(60.5)$ & $200(52.8)$ & $1,898(50.7)$ & $42(28.2)$ \\
\hline Male & $1,792(42.6)$ & $287(47.7)$ & $837(39.4)$ & $178(47.0)$ & $1,843(49.3)$ & $107(71.8)$ \\
\hline Unknown & $0(0.0)$ & $0(0.0)$ & $2(0.1)$ & $1(0.3)$ & $0(0.0)$ & $0(0.0)$ \\
\hline \multicolumn{7}{|l|}{ Age: 1st study period visit, y } \\
\hline $18-29$ & $1,069(25.4)$ & $169(28.1)$ & $544(25.6)$ & $42(11.1)$ & $817(21.8)$ & $48(32.2)$ \\
\hline $30-49$ & $1,793(42.6)$ & $241(40.0)$ & $872(41.0)$ & $142(37.5)$ & $1,478(39.5)$ & $69(46.3)$ \\
\hline $50-64$ & $1,173(27.9)$ & $170(28.2)$ & $551(25.9)$ & $140(36.9)$ & $1,009(27.0)$ & $27(18.1)$ \\
\hline$\geq 65$ & $173(4.1)$ & $22(3.7)$ & $159(7.5)$ & $55(14.5)$ & $437(11.7)$ & $5(3.4)$ \\
\hline \multicolumn{7}{|l|}{ Homeless status } \\
\hline Yes & $64(1.5)$ & $7(1.2)$ & $72(3.4)$ & $13(3.4)$ & $55(1.5)$ & $1(0.7)$ \\
\hline No & $1,858(44.2)$ & $198(32.9)$ & $713(33.5)$ & $114(30.1)$ & $1,299(34.7)$ & $44(29.5)$ \\
\hline Unknown & $2,286(54.3)$ & $397(65.9)$ & $1,341(63.1)$ & $252(66.5)$ & $2,387(63.8)$ & $104(69.8)$ \\
\hline \multicolumn{7}{|l|}{ Migrant/seasonal worker } \\
\hline Yes & $13(0.3)$ & $3(0.5)$ & $47(2.2)$ & $0(0)$ & $7(0.2)$ & $0(0)$ \\
\hline No & $1,911(45.4)$ & $200(33.2)$ & $728(34.2)$ & $131(34.6)$ & $936(25.0)$ & $24(16.1)$ \\
\hline Unknown & $2,284(54.3)$ & $399(66.3)$ & $1,351(63.5)$ & $248(65.4)$ & $2,798(74.8)$ & $125(83.9)$ \\
\hline \multicolumn{7}{|l|}{ Primary payer } \\
\hline Medicaid & $2,957(70.3)$ & $416(69.1)$ & $1,189(55.9)$ & $193(50.9)$ & $2,313(61.8)$ & $84(56.4)$ \\
\hline Medicare & $455(10.8)$ & $52(8.6)$ & $215(10.1)$ & $78(20.6)$ & $567(15.2)$ & $13(8.7)$ \\
\hline Other public & $11(0.3)$ & $2(0.3)$ & $9(0.4)$ & $0(0.0)$ & $5(0.1)$ & $0(0.0)$ \\
\hline Private & $264(6.3)$ & $39(6.5)$ & $299(14.1)$ & $40(10.6)$ & $94(2.5)$ & $4(2.7)$ \\
\hline Uninsured & $521(12.4)$ & $93(15.4)$ & $414(19.5)$ & $68(17.9)$ & $762(20.4)$ & $48(32.2)$ \\
\hline \multicolumn{7}{|l|}{ Primary language } \\
\hline English & $3,915(93.0)$ & $582(96.7)$ & $1,703(80.1)$ & $330(87.1)$ & $2,761(73.8)$ & $126(84.6)$ \\
\hline Spanish & $189(4.5)$ & $6(1.0)$ & $418(19.7)$ & $48(12.7)$ & $336(9.0)$ & $12(8.1)$ \\
\hline Other & $56(1.3)$ & $6(1.0)$ & $4(0.2)$ & $1(0.3)$ & $639(17.1)$ & $11(7.4)$ \\
\hline Unknown & $48(1.1)$ & $8(1.3)$ & $1(0.0)$ & $0(0.0)$ & $5(0.1)$ & $0(0.0)$ \\
\hline \multicolumn{7}{|l|}{ Veteran status } \\
\hline Yes & $118(2.8)$ & $26(4.3)$ & $87(4.1)$ & $17(4.5)$ & $78(2.1)$ & $10(6.7)$ \\
\hline No & $4,049(96.2)$ & $566(94.0)$ & $2,032(95.6)$ & $360(95.0)$ & $3,358(89.8)$ & $112(75.2)$ \\
\hline Unknown & $41(1.0)$ & $10(1.7)$ & $7(0.3)$ & $2(0.5)$ & $305(8.2)$ & $27(18.1)$ \\
\hline \multicolumn{7}{|l|}{ Diabetes status } \\
\hline Yes & $557(13.2)$ & $68(11.3)$ & $279(13.1)$ & $110(29.0)$ & $531(14.2)$ & $7(4.7)$ \\
\hline No & $3,651(86.8)$ & $532(88.4)$ & $1,847(86.9)$ & $269(71.0)$ & $3,210(85.8)$ & $142(95.3)$ \\
\hline Unknown & $0(0.0)$ & $2(0.3)$ & $0(0.0)$ & $0(0.0)$ & $0(0.0)$ & $0(0.0)$ \\
\hline \multicolumn{7}{|l|}{ New/established patients } \\
\hline New patients & $699(16.6)$ & $311(51.7)$ & $239(11.2)$ & $57(15.0)$ & $1,251(33.4)$ & $142(95.3)$ \\
\hline Established patients & $3,509(83.4)$ & $291(48.3)$ & $1,887(88.8)$ & $322(85.0)$ & $2,490(66.6)$ & $7(4.7)$ \\
\hline
\end{tabular}


Table 2. Patient and Visit Characteristics of Patients Seen During the Study Period, and of Those Screened for SDH, by Clinic (continued)

\begin{tabular}{|c|c|c|c|c|c|c|}
\hline \multirow[b]{2}{*}{ Visit Characteristics } & \multicolumn{2}{|c|}{ Clinic A } & \multicolumn{2}{|c|}{ Clinic B } & \multicolumn{2}{|c|}{ Clinic C } \\
\hline & $\begin{array}{l}\text { Total Patients } \\
\text { No. (\%) }\end{array}$ & $\begin{array}{l}\text { Screened } \\
\text { Patients } \\
\text { No. (\%) }\end{array}$ & $\begin{array}{l}\text { Total Patients } \\
\text { No. }(\%)\end{array}$ & $\begin{array}{l}\text { Screened } \\
\text { Patients } \\
\text { No. (\%) }\end{array}$ & $\begin{array}{l}\text { Total Patients } \\
\text { No. (\%) }\end{array}$ & $\begin{array}{l}\text { Screened } \\
\text { Patients } \\
\text { No. (\%) }\end{array}$ \\
\hline Number of visits & $13,990(100.0)$ & $611(4.4)$ & $8,162(100.0)$ & $385(4.7)$ & $16,281(100.0)$ & $149(0.9)$ \\
\hline \multicolumn{7}{|l|}{ Type of practioner } \\
\hline MD, DO, Locum Tenens & $2,686(19.2)$ & $7(1.1)$ & $3,892(47.7)$ & $209(54.3)$ & $7,663(47.1)$ & 149 (100.0) \\
\hline$N P, P A$ & $8,827(63.1)$ & $24(3.9)$ & $2,577(31.6)$ & $76(19.7)$ & $4,399(27.0)$ & $0(0.0)$ \\
\hline RN, LPN, CHN & $1,359(9.7)$ & $187(30.6)$ & $1,427(17.5)$ & $79(20.5)$ & $2,428(14.9)$ & $0(0.0)$ \\
\hline MA & $1,049(7.5)$ & $1(0.2)$ & $59(0.7)$ & $0(0.0)$ & $109(0.7)$ & $0(0.0)$ \\
\hline BHS, LCSW & $\ldots$ & $0(0.0)$ & $181(2.2)$ & $18(4.7)$ & $1,550(9.5)$ & $0(0.0)$ \\
\hline Eligibility specialist & $\ldots$ & $392(64.2)$ & $\ldots$ & $0(0.0)$ & $\ldots$ & $0(0.0)$ \\
\hline Other & $69(0.5)$ & $0(0.0)$ & $26(0.3)$ & $3(0.8)$ & $132(0.8)$ & $0(0.0)$ \\
\hline \multicolumn{7}{|l|}{ Clincian status } \\
\hline Primary care clinician & $7,119(50.9)$ & $22(3.6)$ & $4,439(54.4)$ & $204(53.0)$ & $9,151(56.2)$ & $145(97.3)$ \\
\hline Other & $6,871(49.1)$ & $589(96.4)$ & $3,723(45.6)$ & $181(47.0)$ & $7,130(43.8)$ & $4(2.7)$ \\
\hline
\end{tabular}

text shortcuts to help document domains for when the patient was given SDH-related information or to document if assistance with SDH needs was declined.

\section{Data Collection and Analyses}

We conducted a concurrent ${ }^{44}$ mixed-methods analysis of the pilot clinics' adoption of the SDH data tools from activation in June 2016 through July 2017. The study was extended from 12 to 13 months to assess initial impacts of the tool changes described above. Quantitative and qualitative data were collected simultaneously. Preliminary results from each informed subsequent data collection (eg, discrepancies between interview descriptions of clinic workflows and corresponding quantitative data were further explored in site visits). Final results were compared to validate and confirm analytic interpretations.

Quantitative data, including patient demographic and visit characteristics, were extracted from OCHIN's EHR to describe adult patients (aged $\geq 18$ years) who had SDH data documented in the EHR, or (for comparison) had $\geq 1$ ambulatory visit at a pilot site during the study period. SDH data documented in the EHR was used to describe the prevalence of potential SDH needs. EHR data were also used to quantify SDHrelated referrals and problem list diagnoses.

Qualitative data collection included: workflow observation (6 days) and interviews $(\mathrm{n}=24)$ with diverse care team members involved in collecting and acting on SDH information; and observations of discussions among clinic decision-makers to understand clinic processes of implementing SDH tool use, and barriers and/or facilitators. Data collection and analysis were iterative and inductive $e_{i}$ emergent understanding and questions from preliminary findings were explored. Analyses utilized deductive and inductive coding. ${ }^{45} \mathrm{~A}$ priori codes (conceptual categories) were created for staff role, tool type, and workflow step (eg, data collection, action, reporting) and data-driven codes (eg, specific barriers/facilitators, role of clinic leadership) were identified through data immersion. Analysis followed the constant comparative $\operatorname{method}^{46}{ }_{i}$ new data were compared with previously collected/coded data to detect commonalities/differences, and to develop nuanced understandings of clinic experiences. Once coding was complete we created clinic-specific summaries for cross-site comparison. Regular study team meetings and discussions with stakeholders informed each step of analysis and results interpretation.

This study was approved by the Kaiser Permanente Northwest Institutional Review Board.

\section{RESULTS}

\section{Implementation}

Each clinic first screened a limited population of patients, then scaled up. Clinic A first tested their workflows with a few randomly chosen patients per day, then added all new patients plus those completing annual insurance reauthorizations, and eventually added patients receiving care coordination, HIV services, and behavioral health services. Clinic B began with patients in their diabetes and Hepatitis $C$ case management programs, then added patients aged 65 years and older. Clinic $\mathrm{C}$ first screened new patients seen by a single provider, stopped for a time to address 
barriers related to staff access to and knowledge of the tools, then adopted screening clinic-wide in July 2017, after study data collection had stopped. All 3 clinics: (1) adapted their workflows as needed ${ }_{i}(2)$ principally used the paper-based SDH screening questionnaire, necessitating a data entry workflow step that impacted when the data were available in the EHR and (3) sought to minimize the primary care provider's role in SDH documentation, and in making SDH-related referrals. Supplemental Appendix 2 gives detailed descriptions of the clinics' target populations and workflow iterations (Supplemental Appendix 2, available at http://www. annfammed.org/content/16/5/399/suppl/DC1/).

\section{SDH Screening Documentation and Referrals}

Social determinants of health data were collected on 1,130 patients, representing $4 \%$ to $18 \%$ of adult patients with an ambulatory visit at the pilot clinics during the study period (Table 2 and Table 3 ). Most screened patients ( $97 \%$ to $99 \%$ ) indicated a potential SDH need in $\geq 1 \mathrm{SDH}$ domain; prevalence of needs by domain was similar across sites (Table 4). Among screened patients whose responses indicated $\geq 1$ potential SDH need, 211 (19\%) received an SDHrelated referral. Referral workflows varied by clinic, differentially impacting our ability to determine SDH domains associated with referrals. In Clinic A, patients were referred to community services chosen from the referral tool, linked to an SDH-related diagnosis code, thus facilitating matching referrals to specific needs (Table 4). Clinics B and C routed most SDH

Table 3. Patients Screened for SDH Over Time, by Study Clinic $(\mathrm{N}=1,130)$

\begin{tabular}{|c|c|c|c|}
\hline \multirow[b]{2}{*}{ Month } & \multicolumn{3}{|c|}{ Distinct Patients Screened, No. } \\
\hline & $\begin{array}{c}\text { Clinic A } \\
(n=602)\end{array}$ & $\begin{array}{c}\text { Clinic B } \\
(n=379)\end{array}$ & $\begin{array}{c}\text { Clinic C } \\
(n=149)\end{array}$ \\
\hline Jul 2016 & 1 & 26 & 9 \\
\hline Aug 2016 & 32 & 13 & 31 \\
\hline Sep 2016 & 84 & 8 & 19 \\
\hline Oct 2016 & 78 & 7 & 19 \\
\hline Nov 2016 & 78 & 4 & 27 \\
\hline Dec 2016 & 70 & 22 & 12 \\
\hline Jan 2017 & 78 & 23 & 19 \\
\hline Feb 2017 & 52 & 21 & 13 \\
\hline Mar 2017 & 33 & 10 & 0 \\
\hline Apr 2017 & 21 & 51 & 0 \\
\hline May 2017 & 30 & 101 & 0 \\
\hline Jun 2017 & 28 & 31 & 0 \\
\hline Jul 2017 & 17 & 62 & 0 \\
\hline \multicolumn{4}{|c|}{ SDH $=$ social determinants of health. } \\
\hline \multicolumn{4}{|c|}{$\begin{array}{l}\text { Note: Clinic C data based on encounters with } 1 \text { provider. SDH screening } \\
\text { stopped in Clinic C in February } 2017 \text { for reassessment of workflows and EHR } \\
\text { access policies. }\end{array}$} \\
\hline
\end{tabular}

referrals to community health workers or similar staff; these internal referrals generally lacked the information required to match them to a specific SDH need. In the 3 months after we added questions asking whether patients wanted help with SDH needs, Clinic A screened 68 patients, and Clinic B 182 patients, of whom 62 and 178 (respectively) indicated $\geq 1 \mathrm{SDH}$ need, $15 \%$ of Clinic A patients and $21 \%$ of Clinic B patients with a documented need requested help.

\section{Barriers and Facilitators}

Facilitators to using EHR tools to document SDH included a clinic champion who was trusted, EHR-savvy, able to customize EHR views to support workflows, and willing to use adoption data to iterate workflows. Making it known that SDH data might address reporting requirements increased staff motivation. Key barriers included perceptions that EHR-based SDH data tools: (1) created a fragmented view of the patient, with relevant data in multiple places, and did not readily support documenting a narrative about a given patient ${ }_{i}(2)$ could add a layer of difficulty to collecting and acting

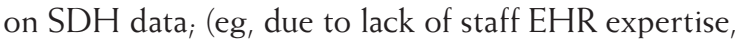
the tools' customized nature, differences in EHR security access by staff role, and the need for new EHR competencies from some staff) $;$ and (3) necessitated a data entry step if SDH information were collected on paper. Referral workflows were seen as too time-consuming, especially when no follow-up was planned ${ }_{i}$ and, until questions asking whether patients desired follow-up for $\mathrm{SDH}$ needs were added, the high positive screening rate yielded an unmanageable follow-up workload (Supplemental Appendix 3, available at http://www.annfammed. org/content/16/5/399/suppl/DC1/).

\section{DISCUSSION}

Our results raise important questions about the feasibility of EHR-based SDH documentation per national recommendations. The argument for such documentation is compelling: SDH profoundly impact health, so providers should know about social factors that might increase their patients' health risks, or hinder their ability to follow care recommendations. An expanding base of literature shows that SDH screening and referral (via paper-based documentation) is associated with improved health outcomes. ${ }^{2}$ Since most health care systems document and track most patient information in EHRs, SDH data should also be in EHRs. Social determinants of health documentation in EHRs could enable care plan adjustments/referrals to social services, and tracking such referrals' results. Furthermore, this documentation could support evaluation of how community referrals impact health and help identify resource gaps 
Table 4. Screening Results and Referral Rates

\begin{tabular}{|c|c|c|c|c|c|c|c|}
\hline \multirow[b]{2}{*}{$\begin{array}{l}\text { Study } \\
\text { Clinic }\end{array}$} & \multirow[b]{2}{*}{$\begin{array}{c}\text { Patients } \\
\text { Screened, } \\
\text { No. }\end{array}$} & \multicolumn{2}{|c|}{ Screened Patients With } & \multirow[b]{2}{*}{ SDH Domain } & \multirow{2}{*}{$\begin{array}{c}\text { Domains for } \\
\text { Patients With } \\
\text { Positive Screen, } \\
\text { No. (\%) }\end{array}$} & \multicolumn{2}{|c|}{$\begin{array}{l}\text { Patients With } \\
\text { Positive Screen } \\
\text { and Matching }\end{array}$} \\
\hline & & $\begin{array}{l}\text { Positive SDH } \\
\text { Screen, } \\
\text { No. (\%) }\end{array}$ & $\begin{array}{c}\text { SDH } \\
\text { Referral, } \\
\text { No. (\%) }\end{array}$ & & & $\begin{array}{c}\text { SDH } \\
\text { Referrala, } \\
\text { No. (\%) }\end{array}$ & $\begin{array}{l}\text { Problem } \\
\text { List dx, } \\
\text { No. (\%) }\end{array}$ \\
\hline \multirow[t]{7}{*}{ A } & 602 & $583(96.8)$ & $141(23.4)$ & Financial resource strain & $426(70.8)$ & $105(24.6)$ & $22(5.2)$ \\
\hline & & & & Housing insecurity & $206(34.2)$ & $60(29.1)$ & $19(9.2)$ \\
\hline & & & & Food insecurity & $331(55.0)$ & $91(27.5)$ & $22(6.6)$ \\
\hline & & & & Intimate partner violence & $175(29.1)$ & $1(0.6)$ & $0(0.0)$ \\
\hline & & & & Inadequate physical activity & $311(51.7)$ & $0(0.0)$ & $0(0.0)$ \\
\hline & & & & Social isolation & $433(71.9)$ & $12(2.8)$ & $4(0.9)$ \\
\hline & & & & Stress & $436(72.4)$ & $0(0.0)$ & $2(0.5)$ \\
\hline \multirow[t]{7}{*}{ B } & 379 & $367(96.8)$ & $26(6.8)$ & Financial resource strain & $277(73.1)$ & $1(0.4)$ & $0(0.0)$ \\
\hline & & & & Housing insecurity & $103(27.2)$ & $3(2.9)$ & $0(0.0)$ \\
\hline & & & & Food insecurity & $216(57.0)$ & $0(0.0)$ & $0(0.0)$ \\
\hline & & & & Intimate partner violence & $94(24.8)$ & $0(0.0)$ & $0(0.0)$ \\
\hline & & & & Inadequate physical activity & $167(44.1)$ & $0(0.0)$ & $0(0.0)$ \\
\hline & & & & Social isolation & $235(62.0)$ & $0(0.0)$ & $0(0.0)$ \\
\hline & & & & Stress & $253(66.8)$ & $0(0.0)$ & $2(0.8)$ \\
\hline \multirow[t]{7}{*}{ C } & 149 & $148(99.3)$ & $44(29.5)$ & Financial resource strain & $107(71.8)$ & $3(2.8)$ & $1(0.9)$ \\
\hline & & & & Housing insecurity & $56(37.6)$ & $3(5.4)$ & $1(1.8)$ \\
\hline & & & & Food insecurity & $86(57.7)$ & $2(2.3)$ & $0(0.0)$ \\
\hline & & & & Intimate partner violence & $36(24.2)$ & $0(0.0)$ & $0(0.0)$ \\
\hline & & & & Inadequate physical activity & $63(42.3)$ & $0(0.0)$ & $0(0.0)$ \\
\hline & & & & Social isolation & $111(74.5)$ & $1(0.9)$ & $0(0.0)$ \\
\hline & & & & Stress & $107(71.8)$ & $1(0.9)$ & $8(7.5)$ \\
\hline
\end{tabular}

in a community, enabling advocacy ${ }^{47}$ and other steps to address health disparities.

Before benefits can be fully realized, the unique challenges of EHR-based SDH documentation and referral-making must be understood and addressed. 1,39,48 Some barriers identified in this study parallel those of other efforts to collect patient-reported data using EHRs, such as difficulties with staff training and turnover, and workflow optimization. ${ }^{49-57}$ While some aspects of the tools were not widely adopted, this is common to such efforts ${ }^{58-61}$; adoption of new EHR tools can take time. Some barriers to SDH screening are likely to occur regardless of the technology used, for example, staff concerns about SDH screening when little intervention is possible. Our findings are consistent with those of a prior case study on EHR-based SDH documentation. ${ }^{62} \mathrm{SDH}$ documentation, review, and referral-making in EHRs can be feasible and useful, but is challenging to adopt. ${ }^{63}$ Despite the many identified challenges to adopting all of the SDH data tools, the study clinics did successfully document $\mathrm{SDH}$ in the EHR, and continued to do so post-study. Referral documentation proved especially challenging. Therefore, to meet the growing national emphasis on EHR-based
SDH documentation and referral, numerous factors must be considered.

When planning for implementation, ensure that new staff are trained in SDH workflows. Consider whether upgrades or other EHR changes may impact $\mathrm{SDH}$ tool use and/or necessitate additional training. Ensure that the correct staff have security access to the tools for the envisioned workflow and appropriate training. Consider conducting a staged rollout of SDH documentation to help identify needed changes in planned workflows. When designing SDH workflows, try to create workflows where data are entered directly in the computer (by staff at point of data collection or through a patient portal). If the workflows involve paper-based data collection, specify staff and the timeframe for data entry, and consider that timing of data entry will impact when, how, and by whom the data can be accessed and used. Consider that the completed paper form does not reveal how a patient scored on the SDH domains; this scoring is not easily identifiable until the data are in the EHR. Make the review of individual patients' SDH data explicit in workflows and emphasize how to locate the summary tools in trainings. If warm hand-offs (eg, referrals to 
community health workers) are desired in the referral workflow, consider: needed staffing, transitions, and rooms; what to do if the right staff person is not available; when to collect SDH data to support this workflow; and different timing options for the hand-off. Consider using roster tools to iteratively review and adjust workflows as necessary.

When designing EHR tools for $\mathrm{SDH}$, vendors and programmers should ensure that documentation identifies if patients (with a SDH need) want assistance with addressing the need and what kind of assistance they want. Consider using text shortcut tools to document provision of community resource materials or referrals provided by SDH topic (this does not provide agency details, but is a fast and easy way to document SDH referrals). Also, consider having the ability to label referrals as "no follow-up needed" when appropriate. Design documentation tools that seamlessly integrate into existing clinic workflows. Expand approaches to documenting patient-reported data without requiring staff data entry (eg, patient portals, data collection computer tablets in clinic waiting and exam rooms, data collection through phone texts). Improve EHRs' capacity to provide updated lists of community resources, and to document and track referrals to those resources.

\section{Limitations}

We could not calculate rates of SDH screening documentation among targeted patients because the study clinics' target populations changed during the study period, the dates of these changes were unclear, and target criteria were not easily extracted from the EHR These differentially targeted groups also underlie variation in the characteristics of screened vs unscreened patients, so such differences cannot be interpreted as related to EHR-based SDH screening. The groups initially targeted for screenings were chosen by the clinics for pragmatic reasons, in that they were relatively easy to identify. Therefore, it is unlikely that the high rate of positive screening results reflects the patients targeted for screening.

It is possible that our count of screened patients may be low, and prevalence of SDH needs among screened patients may be higher than in the clinics' overall population, as some data from paper surveys were likely not entered into EHRs, especially if no SDH needs were identified. For example, some clinic counts of patients screened did not match our quantitative data from the $\mathrm{EHR}_{i}$ further, we observed that data entry workflows were not always standardized. Similarly, referral rates are likely underestimated ; qualitative data suggests that community resource referrals were often documented in chart notes rather than in discrete fields in the EHR, so could not be readily tracked quantitatively. We were unable to assess changes in SDH status, care quality, or biomarkers, as the study sites chose to conduct SDH documentation annually within a 1-year analysis period. We were unable to quantify how often the SDH summary was accessed, or by whom, because no data entry was involved in use of this tool. The SDH screening measures used here have not been validated as predictive of specific outcomes; far more research is needed in this area. Finally, this pilot study involved a single EHR system $_{i}$ the tools and workflows discussed here may not be transferable to other systems.

\section{CONCLUSION}

This pilot study is the first to formally test adoption of EHR-based SDH data documentation, review, and action in $\mathrm{CHCs}$, and is one of the first in any clinical setting. Our results suggest that $\mathrm{SDH}$ documentation in EHRs is feasible; however, for the benefits of systematic EHR-based SDH documentation to be realized, barriers to adoption of EHR tools must be addressed. Results may be informative to $\mathrm{CHCs}$ and other primary care providers seeking to implement SDH-related efforts, especially if SDH documentation becomes required or associated with financial incentives. Far more research is needed in this area, including: optimal methods for collecting SDH data into EHRs at or before clinic visits; strategies for implementing EHR-based SDH documentation and review into standard workflows; and optimal methods for linking clinics to community services and maintaining resource lists. The systematic EHR documentation and management of SDH needs could impact CHC patients' health, but optimizing such EHR tools and integrating them smoothly into clinic workflows will require addressing substantial knowledge gaps.

To read or post commentaries in response to this article, see it online at http://www.AnnFamMed.org/content/16/5/399.

Key words: social determinants of health; electronic health records; community health centers; implementation

Submitted December 18, 2017; submitted, revised, April 11, 2018; accepted May 2, 2018.

Funding support: This publication was supported by a grant from the National Institute of Diabetes and Digestive and Kidney Diseases (NIDDK), R18DK105463.

Previous presentations: The results of this study were presented at the American Medical Informatics Association conference; November 4-8, 2017; Washington, DC; the $45^{\text {th }}$ Annual North American Primary Care Research Group meeting; November 17-21, 2017; Montreal, Canada; and the Society for Implementation Research Conference; September 8-9, 2017; Seattle, Washington.

Acknowledgments: The authors deeply appreciate the contributions of staff at our pilot sites, Jennifer Hale, RN, James Stoltz, RN, Carla 
Remeschatis, and Maria Zambrano, who provided feedback on clinic workflows and implementation efforts. We would also like to thank collaborators, Ranu Pandey, MHA, and Matthew C. Stiefel, MS, MPA (Kaiser Permanente Care Management Institute), and OCHIN's Clinical Operations Review Committee (CORC) for their input on development of the SDH Data Tools.

Supplemental Materials: Available at http://www.AnnFamMed. org/content/16/5/399/suppl/DC1/.

\section{References}

1. Thomas-Henkl C, Schulman M. Screening for social determinants of health in populations with complex needs: implementation considerations. https://www.chcs.org/media/SDOH-Complex-CareScreening-Brief-102617.pdf. Published 2017.

2. Gottlieb LM, Wing H, Adler NE. A systematic review of interventions on patients' social and economic needs. Am J Prev Med. 2017; 53(5):719-729.

3. Institute for Alternative Futures. Community health centers leveraging the social determinants of health. http://www.altfutures.org/ pubs/leveragingSDH/IAF-CHCsLeveragingSDH.pdf. Published 2012.

4. Bachrach D, Pfister H, Wallis K, Lipson M. Addressing Patients' Social Needs: An Emerging Business Case for Provider Investment. New York, NY: The Commonwealth Fund; 2014.

5. World Health Organization. Social determinants of health: about social determinants of health. http://www.who.int/social_determinants/sdh_definition/en/. Published 2017. Accessed Nov 29, 2017.

6. U. S. Department of Health \& Human Services (DHHS). Healthy People 2010, 2nd Edition. Washington, DC: US Government Printing Office; 2000.

7. Frieden TR. A framework for public health action: the health impact pyramid. Am J Public Health. 2010;100(4):590-595.

8. Fenton. Health Care's Blind Side: The Overlooked Connection between Social Needs and Good Health. Princton, NJ: Robert Wood Johnson Foundation; 2011. 9. Woolf SH, Johnson RE, Phillips RL Jr, Philipsen M. Giving everyone the health of the educated: an examination of whether social change would save more lives than medical advances. Am J Public Health. 2007;97(4):679-683.

10. Hämmig O, Bauer GF. The social gradient in work and health: a cross-sectional study exploring the relationship between working conditions and health inequalities. BMC Public Health. 2013;13:1170.

11. Krieger N, Kosheleva A, Waterman PD, Chen JT, Beckfield J, Kiang MV. 50-year trends in US socioeconomic inequalities in health: US-born Black and White Americans, 1959-2008. Int J Epidemiol. 2014:43(4):1294-1313.

12. Lahiri S, Moure-Eraso R, Flum M, Tilly C, Karasek R, Massawe E. Employment conditions as social determinants of health. Part I: the external domain. New Solut. 2006;16(3):267-288.

13. Moure-Eraso R, Flum M, Lahiri S, Tilly C, Massawe E. A review of employment conditions as social determinants of health part II: the workplace. New Solut. 2006;16(4):429-448.

14. Lahelma E, Laaksonen M, Aittomäki A. Occupational class inequalities in health across employment sectors: the contribution of working conditions. Int Arch Occup Environ Health. 2009;82(2):185-190.

15. Kawachi I, Berkman LF. Neighborhoods and Health. Oxford, England: Oxford University Press; 2003.

16. Garg A, Butz AM, Dworkin PH, Lewis RA, Thompson RE, Serwint JR. Improving the management of family psychosocial problems at low-income children's well-child care visits: the WE CARE Project. Pediatrics. 2007;120(3):547-558.

17. Garg A, Sarkar S, Marino M, Onie R, Solomon BS. Linking urban families to community resources in the context of pediatric primary care. Patient Educ Couns. 2010;79(2):251-254.
18. Gottlieb LM, Hessler D, Long D, et al. Effects of social needs screening and in-person service navigation on child health: a randomized clinical trial. JAMA Pediatr. 2016;170(11):e162521.

19. McClintock HF, Bogner HR. Incorporating patients' social determinants of health into hypertension and depression care: a pilot randomized controlled trial. Community Ment Health J. 2017;53(6): 703-710.

20. Berkowitz SA, Hulberg AC, Standish S, Reznor G, Atlas SJ. Addressing unmet basic resource needs as part of chronic cardiometabolic disease management. JAMA Intern Med. 2017;177(2):244-252.

21. Institute of Medicine. Recommended social and behavioral domains and measures for electronic health http://nationalacademies.org/ HMD/Activities/PublicHealth/SocialDeterminantsEHR.aspx. Published 2014.

22. Institute of Medicine; Committee on the Recommended Social Behavioral Domains and Measures for Electronic Health Records. Capturing Social and Behavioral Domains and Measures in Electronic Health Records, PHASE 2. Washington, DC: National Academies Press; 2014.

23. Health Information Technology Advisory Committee (HITAC). Meaningful use stage 3 final recommendations. https://www. healthit.gov/sites/default/files/facas/HITPC_MUWG_Stage3_ Recs_2014-04-01.pdf. Published 2017.

24. Centers for Medicare \& Medicaid Services. MARCA: delivery system reform, Medicare payment reform. https://www.cms.gov/Medicare/ Quality-Initiatives-Patient-Assessment-Instruments/Value-BasedPrograms/MACRA-MIPS-and-APMs/MACRA-MIPS-and-APMs.html. Accessed Sep 9, 2016.

25. The Office of the National Coordinator for Health Information Technology (ONC). Federal health IT strategic plan. https://www. healthit.gov/sites/default/files/9-5-federalhealthitstratplanfinal_0. pdf. Published 2016.

26. Bailey SR, O'Malley JP, Gold R, Heintzman J, Marino M, DeVoe JE. Receipt of diabetes preventive services differs by insurance status at visit. Am J Prev Med. 2015;48(2):229-233.

27. Gold R, DeVoe JE, McIntire PJ, Puro JE, Chauvie SL, Shah AR. Receipt of diabetes preventive care among safety net patients associated with differing levels of insurance coverage. J Am Board Fam Med. 2012;25(1):42-49.

28. Gold R, DeVoe J, Shah A, Chauvie S. Insurance continuity and receipt of diabetes preventive care in a network of federally qualified health centers. Med Care. 2009;47(4):431-439.

29. Stringhini S, Batty GD, Bovet $P$, et al. Association of lifecourse socioeconomic status with chronic inflammation and type 2 diabetes risk: the Whitehall II prospective cohort study. PLOS Med. 2013; 10(7):e1001479.

30. Hsu CC, Lee $\mathrm{CH}$, Wahlqvist ML, et al. Poverty increases type 2 diabetes incidence and inequality of care despite universal health coverage. Diabetes Care. 2012;35(11):2286-2292.

31. Lysy Z, Booth GL, Shah BR, Austin PC, Luo J, Lipscombe LL. The impact of income on the incidence of diabetes: a population-based study. Diabetes Res Clin Pract. 2013;99(3):372-379.

32. Sacerdote C, Ricceri F, Rolandsson O, et al. Lower educational level is a predictor of incident type 2 diabetes in European countries: the EPIC-InterAct study. Int J Epidemiol. 2012;41(4):1162-1173.

33. Jones-Smith JC, Karter AJ, Warton EM, et al. Obesity and the food environment: income and ethnicity differences among people with diabetes: the Diabetes Study of Northern California (DISTANCE). Diabetes Care. 2013;36(9):2697-2705.

34. Lee $H A$, Lee KE, Jeong YW, et al. How do life-course trajectories of socioeconomic position affect quality of life in patients with diabetes mellitus? Qual Life Res. 2014;23(4):1337-1344.

35. Anekwe TD, Rahkovsky I. The association between food prices and the blood glucose level of US adults with type 2 diabetes. Am J Public Health. 2014;104(4):678-685. 
36. Muennig P, Franks $P$, Jia H, Lubetkin E, Gold MR. The incomeassociated burden of disease in the United States. Soc Sci Med. 2005;61(9):2018-2026.

37. Adashi EY, Geiger HJ, Fine MD. Health care reform and primary care-the growing importance of the community health center. $N$ Engl J Med. 2010;362(22):2047-2050.

38. The Menges Group. Positively impacting social determinants of health: how safety net health plans lead the way. http://www. communityplans.net/Portals/0/Fact\%20Sheets/ACAP_Plans_and_ Social_Determinants_of_Health.pdf. Published Jun 2014.

39. Byhoff E, Freund KM, Garg A. Accelerating the implementation of social determinants of health interventions in internal medicine. J Gen Intern Med. 2018;33(2):223-225.

40. Gold R, Cottrell E, Bunce A, et al. Developing electronic health record (EHR) strategies related to health center patients' social determinants of health. J Am Board Fam Med. 2017;30(4):428-447.

41. Institute of Medicine; Board on Population Health and Public Health Practice: Committee on the Recommended Social and Behavioral Domains and Measures for Electronic Health Records. Capturing Social and Behavioral Domains in Electronic Health Records: Phase 1. Washington, DC: National Academies Press;2014.

42. National Association of Community Health Centers. PRAPARE. http://www.nachc.org/research-and-data/prapare/. Published 2016. Accessed Feb 23, 2017.

43. Powell BJ, Waltz TJ, Chinman MJ, et al. A refined compilation of implementation strategies: results from the Expert Recommendations for Implementing Change (ERIC) project. Implement Sci. 2015; 10:21.

44. Creswell J, Plano Clark V. Designing and Conducting Mixed Methods Research. Thousand Oaks, CA: Sage; 2007.

45. Braun V, Clarke V. Using thematic analysis in psychology. Qual Res Psychol. 2006;3(2):77-101.

46. Glasser B. The constant comparative method of qualitative analysis. Soc Probl. 1965;12(4):436-445.

47. DeVoe JE, Bazemore AW, Cottrell EK, et al. Perspectives in primary care: a conceptual framework and path for integrating social determinants of health into primary care practice. Ann Fam Med. 2016;14(2):104-108.

48. Hripcsak G, Forrest CB, Brennan PF, Stead WW. Informatics to support the IOM social and behavioral domains and measures. J Am Med Inform Assoc. 2015;22(4):921-924.

49. Bryan S, Davis J, Broesch J, et al. Choosing your partner for the PROM: a review of evidence on patient-reported outcome measures for use in primary and community care. Healthcare policy = Politiques de sante. 2014;10(2):38-51.
50. Spertus J. Barriers to the use of patient-reported outcomes in clinical care. Circ Cardiovasc Qual Outcomes. 2014;7(1):2-4.

51. Nelson EC, Eftimovska E, Lind C, Hager A, Wasson JH, Lindblad S. Patient reported outcome measures in practice. BMJ. 2015;350: g7818.

52. Boyce MB, Browne JP, Greenhalgh J. The experiences of professionals with using information from patient-reported outcome measures to improve the quality of healthcare: a systematic review of qualitative research. BMJ Qual Saf. 2014;23(6):508-518.

53. Hostetter MK. S. Using Patient-Reported Outcomes to Improve Health Care Quality. New York, NY: The Commonwealth Fund;2012.

54. Ivanova JI, Birnbaum HG, Schiller M, Kantor E, Johnstone BM, Swindle RW. Real-world practice patterns, health-care utilization, and costs in patients with low back pain: the long road to guideline-concordant care. Spine J. 2011;11(7):622-632.

55. Ridgeway JL, Beebe TJ, Chute CG, et al. A brief Patient-Reported Outcomes Quality of Life (PROQOL) instrument to improve patient care. PLoS Med. 2013;10(11):e1001548.

56. Jensen RE, Rothrock NE, DeWitt EM, et al. The role of technical advances in the adoption and integration of patient-reported outcomes in clinical care. Med Care. 2015;53(2):153-159.

57. Campbell R. The five "rights" of clinical decision support. J AHIMA. 2013;84(10):42-47, quiz 48.

58. McCullagh LJ, Sofianou A, Kannry J, Mann DM, McGinn TG. User centered clinical decision support tools: adoption across clinician training level. Appl Clin Inform. 2014;5(4):1015-1025.

59. Heisey-Grove D, Danehy LN, Consolazio M, Lynch K, Mostashari F. A national study of challenges to electronic health record adoption and meaningful use. Med Care. 2014;52(2):144-148.

60. Rittenhouse DR, Ramsay PP, Casalino LP, McClellan S, Kandel ZK, Shortell SM. Increased health information technology adoption and use among small primary care physician practices over time: a national cohort study. Ann Fam Med. 2017;15(1):56-62.

61. Stehlik J, Rodriguez-Correa C, Spertus JA, et al. Implementation of real-time assessment of patient-reported outcomes in a heart failure clinic: a feasibility study. J Card Fail. 2017;23(11):813-816.

62. Gottlieb LM, Tirozzi KJ, Manchanda R, Burns AR, Sandel MT. Moving electronic medical records upstream: incorporating social determinants of health. Am J Prev Med. 2015;48(2):215-218.

63. LaForge K, Gold R, Cottrell E, et al. How 6 organizations developed tools and processes for social determinants of health screening in primary care: an overview. J Ambul Care Manage. 2018;41(1):2-14. 